\title{
DON'T FORGET TO RENEW YOUR GDC REGISTRATION!
}

The Annual Renewal period for all dental care professionals (DCPs) in the UK is open and must be completed no later than 31 July 2019 in order to stay on the Register for the following 12-month period.

There are three steps to renewing registration. DCPs must:

- Pay the Annual Retention Fee (ARF)

- Make an annual continuing professional development (CPD) statement (or end-of-cycle statement if individual's five-year cycle ends on 31 July)

- Declare they have, or will have, appropriate indemnity in place.

The quickest and easiest way to complete the Annual Renewal is through eGDC (https://www.gdc-uk.org/professionals/ egdc), and it takes only five minutes to register to use the service if not already set up.

Since the introduction of Enhanced CPD in 2018, all DCPs must make an annual CPD statement. This entails confirming how many hours of CPD have been completed in the previous 12 months (even if that figure is 'zero') and making a declaration that the CPD completed is relevant to their field of practice, a CPD record including a personal development has been kept and the statement is full and accurate.

GDC Executive Director, Registration and Corporate Resources, Gurvinder Soomal, said: 'This is the first year that annual enhanced CPD statements have been part of the DCP Annual Renewal process, and we would like to remind people of those requirements, including new requirements for zero hour declarations. [...] I really would urge people not to leave it until the last minute and to get in touch with us as soon as possible if they have any questions.

Enhanced CPD also brought changes to the rules governing how 'grace period'

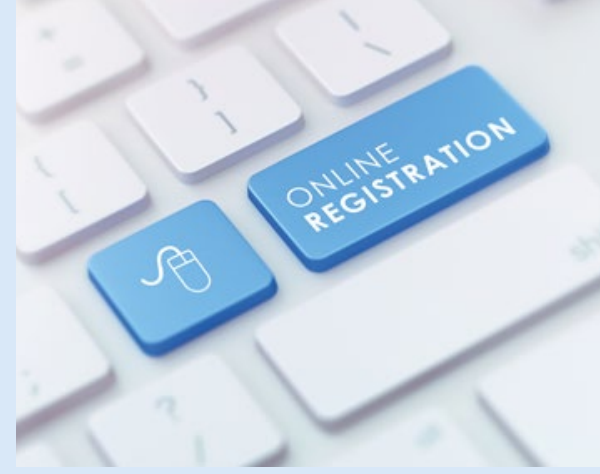

applications are made. Grace is available for those who, due to exceptional circumstances, need further time to complete the required number of hours for their five-year CPD cycle. Under Enhanced $\mathrm{CPD}$, applications must be made no later than 31 July.

The GDC provides further guidance and information about Enhanced CPD on its website: https://www.gdc-uk.org/ professionals/cpd/ enhanced-cpd.

\section{CPD?}

Looking to top up your verifiable CPD hours? BDJ Team offers one free hour every time a new issue is published online. At the moment you can complete all ten hours of verifiable CPD from 2018 and seven (to date) from 2019. Visit https://go.nature. $\mathrm{com} / 2 \mathrm{~F} 4 \mathrm{kqDm}$

\section{DENTAL NURSES AT THE DENTISTRY SHOW}

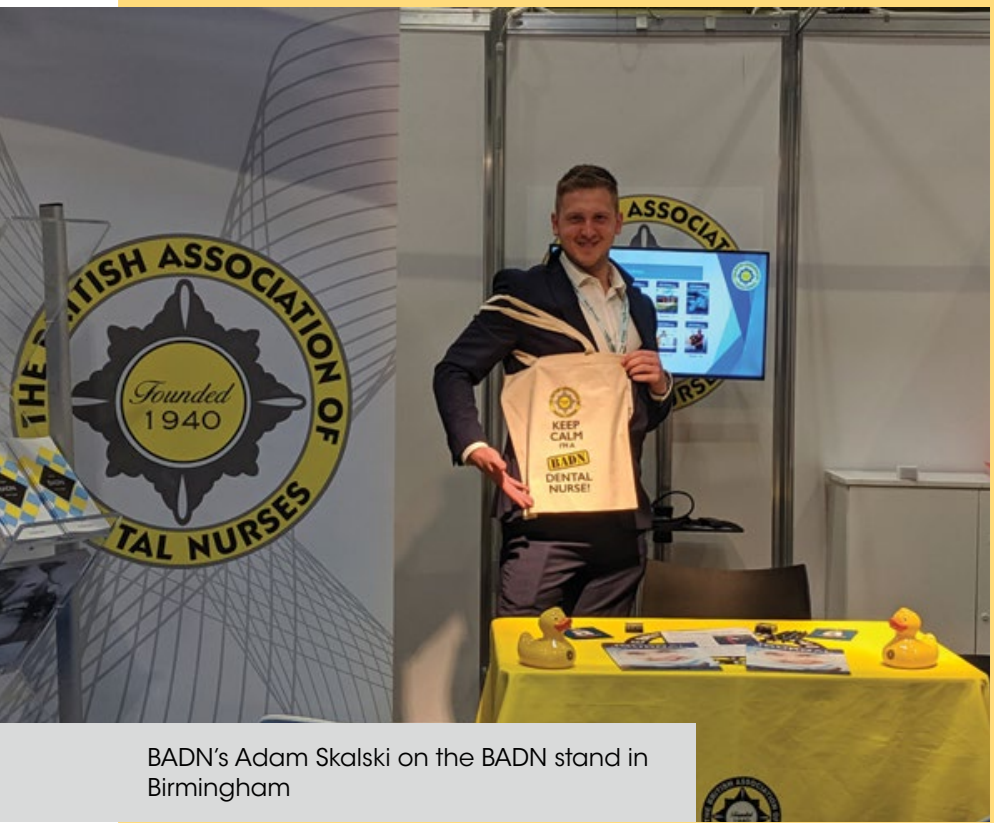

BADN's Adam
Birmingham

Dental nurses attending the recent British Dental Conference and Dentistry Show at the NEC in Birmingham had two focal points: the British Association of Dental Nurses (BADN) stand, and the Dental Nurse Forum.
Dental nurses visited the BADN stand in their droves, to join, renew or find out about the new BADN website/CRM system. IT \& Comms Administrator Adam Skalski demonstrated to members how to log in and set up their member accounts on his trusty iPad, whilst Chief Exec Pam Swain answered visitors' questions and handed out BADN bags containing a BADN savings duck, BADN pen, membership badge and copy of the British Dental Nurses' Journal to members and those joining at the stand.

The Dental Nurse Forum, co-organised by BADN and chaired by BADN President Hazel Coey, was very well attended over the two days. Presentations at the Forum included BADN's own Jane Dalgarno on The Use of Mentoring to Support Professional Development (including information on BADN's soon-to-beannounced mentoring platform), and President-elect Jacqui Elsden on Dental Nursing: What Lies Ahead?

Other speakers included the always popular Isis Buffonge of UCL Eastman on Effective Implant Nursing; Max O'Neill - who stood in at the last moment - on Dealing with Difficult People; Simon Wright on Human Error; HEE's Mike Wheeler on New Routes of Progression for the Dental Team; and the GDC on Moving Upstream/Shifting the Balance.

The next big event for dental nurses is the National Dental Nursing Conference, to be held on 1-2 November 2019 at the Oxford Spires Hotel (read more about this event in a special feature this July in $B D J$ Team).

For more information on the benefits of BADN Membership, or on the National Dental Nursing Conference, visit www. badn.org.uk. 